\title{
Correction to: The novel fetal MRI O/E CLV versus O/E LHR in predicting prognosis in congenital diaphragmatic hernias: can we teach an old dog new tricks?
}

\author{
Ryan Phillips ${ }^{1,2} \cdot$ Maxene Meier $^{3} \cdot$ Niti Shahi $^{1,2} \cdot$ Stephen Niemiec $^{1,2} \cdot$ Sarah Ogle $^{1,2}$ - Marina L. Reppucci ${ }^{1,2}$. \\ Shannon Acker ${ }^{1,2} \cdot$ Jason Gien ${ }^{4,5} \cdot$ Kenneth W. Liechty ${ }^{4,5} \cdot$ Mariana L. Meyers $^{4} \cdot$ Ahmed Marwan $^{1,4,5}$
}

Published online: 15 October 2021

(c) Springer-Verlag GmbH Germany, part of Springer Nature 2021

\section{Correction to: Pediatric Surgery International https://doi.org/10.1007/s00383-021-04936-9}

In the original publication, one of the co-author name Marina L. Reppucci was missed to include in the author group. The correct author group should read as follows:

Ryan Phillips, Maxene Meier, Niti Shahi, Stephen Niemiec, Sarah Ogle, Marina L. Reppucci, Shannon Acker, Jason Gien, Kenneth W. Liechty, Mariana L. Meyers, Ahmed Marwan

Dr Marina L. Reppucci's affiliation is:

Division of Pediatric Surgery, Children's Hospital Colorado, Aurora, CO, USA

Department of Surgery, University of Colorado School of Medicine, Aurora, CO, USA

Publisher's Note Springer Nature remains neutral with regard to jurisdictional claims in published maps and institutional affiliations.

The original article can be found online at https://doi.org/10.1007/ s00383-021-04936-9.

Ryan Phillips

ryan.phillips@childrenscolorado.org

1 Division of Pediatric Surgery, Children's Hospital Colorado, Aurora, CO, USA

2 Department of Surgery, University of Colorado School of Medicine, Aurora, CO, USA

3 Center for Research in Outcomes for Children's Surgery, Center for Children's Surgery, University of Colorado School of Medicine, Aurora, CO, USA

4 Colorado Fetal Care Center, Colorado Institute of Maternal and Fetal Health, Anschutz Medical Center, University of Colorado Denver, Denver, USA

5 Department of Pediatrics, Division of Neonatology, University of Colorado School of Medicine, Aurora, CO, USA 